JAYME, C.G. et al. Suplementação de bovinos de corte a pasto durante o período seco.

PUBVET, Londrina, V. 7, N. 24, Ed. 247, Art. 1630, Dezembro, 2013.

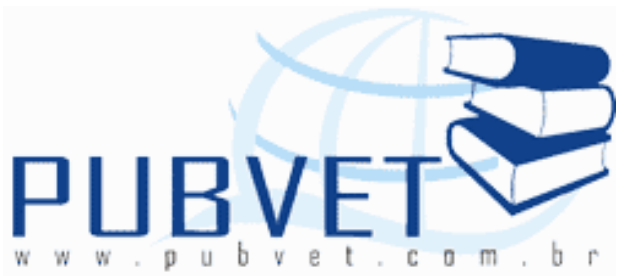

PUBVET, Publicações em Medicina Veterinária e Zootecnia.

\title{
Suplementação de bovinos de corte a pasto durante o período seco
}

Cristiano Gonzaga Jayme" ; Paulo César Santos Oliveira²; Angelo Herbet Moreira Arcanjo²; Larissa Cotta Moreira²; Diogo Gonzaga Jayme ${ }^{3}$

1 Professor do Instituto Federal de Educação, Ciência e Tecnologia Sudeste de Minas Gerais - Campus Rio Pomba.

E-mail: cristiano.jayme@ifsudestemg.edu.br

2 Graduando em Zootecnia do Instituto Federal de Educação, Ciência e Tecnologia Sudeste de Minas Gerais - Campus Rio Pomba.

3 Professor adjunto da Escola de Veterinária da Universidade Federal de Minas Gerais.

\section{Resumo}

A bovinocultura de corte é baseada em sistemas de produção que incluem pastagens nativas e/ou cultivadas, e a produção animal está condicionada à quantidade e qualidade da pastagem consumida. As estratégias de suplementação visam reduzir o período de ocupação dos animais nas pastagens, otimizando a utilização das forrageiras nos períodos críticos do ano, onde as mesmas possuem baixo valor nutricional, principalmente no teor de proteína. Entre os vários tipos de suplementação para animais a pasto, destaca-se mistura sal mineral-uréia, misturas múltiplas e suplementação com concentrados protéicos. Programas de suplementação a pasto proporcionam ganhos de peso de 0,200 a 0,990 $\mathrm{kg}$ com consumo variando de 
JAYME, C.G. et al. Suplementação de bovinos de corte a pasto durante o período seco. PUBVET, Londrina, V. 7, N. 24, Ed. 247, Art. 1630, Dezembro, 2013.

0,3 a $1 \%$ do PV. O uso das alternativas de suplementação representa opção para que sistemas de produção de bovinos sejam otimizados possibilitando maior eficiência produtiva na atividade pecuária.

Palavras-chave: Gado de corte, pasto, suplementação, período seco.

\title{
Supplementation of grass fed meat cattle during the dry season
}

\begin{abstract}
The meat cattle is based in systems of output that include native pastures and/or cultivated, and the animal output is conditioned to the quantity and quality of the pasture consumed. The strategies of supplementation are going to reduce the period of occupation of the animals in the pastures, optimizing the utilization of the forage crops in the critics periods of the year, where the same possess bass nutritional value, mainly in the content of protein. Between the several kinds of supplementation for animals from grass, we highlight mineral-urea salt mixture, multiple mixtures and supplementation with concentrated protein. Supplementation from grass will provide profits of weight of 0.200 to $0.990 \mathrm{~kg}$ with consumption varying of 0.3 to $1 \%$ of the live weight. The use of supplement alternatives represents an option to improve cattle production so that is optimized enabling higher productive efficiency in the activity livestock farming.
\end{abstract}

Keywords: Cattle, pasture, supplementation, dry period

\section{Introdução}

No Brasil a bovinocultura de corte é baseada em sistemas de produção que incluem pastagens nativas e/ou cultivadas, e a produção animal está condicionada à quantidade e qualidade da pastagem consumida. Segundo o ANUALPEC (2011), cerca de 93\% dos bovinos abatidos em 2010 foram terminados a pasto ou com algum tipo de suplementação. Esse dado realça a 
JAYME, C.G. et al. Suplementação de bovinos de corte a pasto durante o período seco. PUBVET, Londrina, V. 7, N. 24, Ed. 247, Art. 1630, Dezembro, 2013.

importância que a suplementação a pasto representa para a cadeia produtiva da carne no Brasil.

A crescente demanda do mercado por carne bovina de qualidade, proveniente de animais criados a pasto, faz com que o Brasil adote novas tecnologias para viabilização de uma pecuária moderna e de ciclo curto (Carvalho et al.,2003). As estratégias de suplementação visam reduzir o período de ocupação dos animais nas pastagens, otimizando a utilização das forrageiras nos períodos críticos do ano, onde as mesmas possuem baixo valor nutricional.A quantidade diária de matéria seca consumida é uma medida crítica para se fazer inferências nutricionais e se alcançar um balanço positivo entre a oferta e demanda por nutrientes do animal em pastejo (Paulino, 2003).

Os planos de alimentação deverão garantir alimentos que em quantidade e qualidade cubram todas as necessidades de consumo de matéria seca e, corrigir desequilíbrios nutricionais, porventura existentes, com as devidas correções táticas e ou estratégicas (Paulino, 2003).

Embora os sistemas de produção de bovinos em pastejo envolvendo suplementação apresentem naturalmente maior variabilidade econômica e de desempenho animal, constituem uma opção viável para os pecuaristas, pois além de não requererem atividade agrícola para produção de volumosos, como requerem os confinamentos, permitem significativas melhorias nos índices de produtividade do rebanho e melhoram as condições de manejo das pastagens.

O objetivo do presente trabalho foi levantar as principais formas de suplementação de animais mantidos a pasto.

\section{Alternativas de suplementação}

A suplementação de animais no pastejo de maneira geral tem os objetivos de corrigir as deficiências de nutrientes das forragens, aumentar a 
JAYME, C.G. et al. Suplementação de bovinos de corte a pasto durante o período seco. PUBVET, Londrina, V. 7, N. 24, Ed. 247, Art. 1630, Dezembro, 2013.

capacidade de suporte das pastagens, fornecer aditivos ou promotores de crescimento e auxiliar no manejo de pastagens (Reis et al., 1997).

Entre os vários tipos de suplementação para animais a pasto, destaca-se mistura sal mineral-uréia (proteinado), misturas múltiplas e suplementação com concentrados proteicos.

Moreira et al. (2004) suplementando novilhos nelore terminados em pastagem com utilização de sal mineral proteinado, obtiveram ganho de 0,150 kg.dia-1 com consumo de 400g.dia de suplemento, quando comparado a uma ingestão de 290g.dia-1. Vilela et al. (1981) estudando o efeito da adição de uréia ao suplemento mineral de bezerros desmamados encontrou valores positivos médios de 0,$280 ; 0,370$; e $0,460 \mathrm{~kg}$ de ganho de peso por dia com a proporção de 0, 25 e 50\% de uréia na mistura mineral, comprovando a eficiência deste tipo de suplementação durante o período seco.

A mistura múltipla caracteriza-se por conter uréia (nitrogênio não orgânico), fontes de proteína natural (nitrogênio orgânico), de energia, fósforo, cálcio, microelementos, além do sal comum, que juntamente com a uréia é fator limitante de consumo pelo gado. Ao avaliar o desempenho de tourinhos nelore na fase de recria suplementados com mistura múltipla, Porto et. al (2012) relataram que as melhores respostas de desempenho e características nutricionais podem ser obtidas com o fornecimento diário de níveis de 0,5 a $1,34 \mathrm{~kg} /$ suplemento/animal/dia.

Os concentrados proteicos são formulados com fontes proteicas e energéticas e suplemento mineral, afim de se atingir um teor proteico acima de $20 \%$. As forragens são a principal fonte energética de bovinos em pastejo, porém, durante o período seco do ano, partes dos nutrientes tornam-se indisponíveis, notadamente pelo efeito de proteção da lignina sobre os carboidratos fibrosos, o que incorre em elevada demanda por recursos suplementares (Van Soest, 1994; Paulino et al., 2006a). Paula et al. (2010) 
JAYME, C.G. et al. Suplementação de bovinos de corte a pasto durante o período seco. PUBVET, Londrina, V. 7, N. 24, Ed. 247, Art. 1630, Dezembro, 2013.

obtiveram ganhos 0,500 a $0,670 \mathrm{~kg} / \mathrm{dia}$ ao suplementar animais anelorados com concentrados proteicos compostos por farelo de soja ou farelo de algodão.

O consumo pode variar dependendo da formulação. O uso crescente de sal comum e uréia funcionam como reguladores de consumo das misturas, podendo variar de 0,05 a $0,5 \%$ do peso vivo.

O consumo dos suplementos é afetado também pela fertilidade do solo, tipo de forragem consumida, variação individual, salinidade da água, palatabilidade da mistura mineral, disponibilidade do suplemento em boas condições físicas e forma física da mistura.

\section{Suplementação a pasto}

As pastagens tropicais, especialmente durante a época seca, raramente constituem uma "dieta balanceada" no senso que seus constituintes orgânicos e inorgânicos estejam presentes nas concentrações e proporções que melhor satisfaçam as necessidades dos animais. Neste contexto, os bovinos geralmente sofrem de carências múltiplas, envolvendo proteína, energia, minerais e vitaminas. A perda de peso de bovinos em pastagens secas no inverno é evidente e parece resultar da redução no consumo de nutrientes digestíveis. Isto pode ser devido aos decréscimos na proteína, conteúdo mineral e digestibilidade que ocorrem em gramíneas supermaduras (Paulino et al., 1982). Este fato resulta nos baixos índices zootécnicos observados na pecuária de corte (Reis et al.,1997).

Assim, na suplementação a pasto deve-se levar em consideração a ocorrência de deficiências simultâneas, estabelecendo-se suplementos de natureza múltipla, envolvendo a associação de fontes de nitrogênio solúvel, minerais, fontes naturais de proteína, energia e vitaminas, visando proporcionar o crescimento contínuo dos bovinos em pastejo, uma vez que para desempenho ótimo todos estes fatores alimentares devem estar em balanço adequado na dieta (Paulino, 2003). 
JAYME, C.G. et al. Suplementação de bovinos de corte a pasto durante o período seco. PUBVET, Londrina, V. 7, N. 24, Ed. 247, Art. 1630, Dezembro, 2013.

Neste período, de todos os nutrientes, o nitrogênio é mais limitante, e consequentemente 0 de maior prioridade para suplementação. Sua participação na dieta do animal é fundamental para manter o crescimento normal das bactérias ruminais. Para Van Soest (1994), a depressão do consumo pode ser atribuída à deficiência de $\mathrm{N}$ para o animal, à redução na fermentação ruminal ou à menor saída de resíduos não digeridos do rúmen. Assim, apesar da clássica associação de digestibilidade com teor de lignina, a proteína não seria ignorada quando se avalia a qualidade geral de forragens. O período seco do ano restringe o crescimento das gramíneas tropicais, que apresentam neste período baixo valor nutritivo e teor proteico inferior ao valor mínimo de 7,0\% para que os microrganismos tenham condições de utilizar os substratos energéticos fibrosos da forragem ingerida (Lazzarini et al., 2009). Hennessy (1985) estudaram suplementos protéicos ou energéticos e suas combinações e verificaram, em dietas de gramíneas de baixa qualidade, que a melhor resposta foi obtida com suplemento proteico, confirmando assim a deficiência de proteína das forragens na época da seca.

A deficiência ruminal de compostos nitrogenados $(N)$, seja na forma de amônia, aminoácidos ou peptídeos pode influenciar a regulação da ingestão de alimentos. Quando o suprimento, originário do material ingerido ou de reciclagem endógena, não atende aos requisitos microbianos, ocorrem limitações do crescimento microbiano e depressão da digestão da parede celular, resultando em diminuição do consumo (Sniffenet al., 1992).

Cerca de $75 \%$ do carboidrato digerido pelos ruminantes é fermentado pelos microrganismos no rúmen, estes suprindo cerca de $50 \%$ da proteína necessária pelo ruminante. Sob condições de pastejo, a primeira consideração a ser feita, seria atender as necessidades ruminais de nitrogênio para assegurar o consumo e a digestão de forragem. Com pastagens pobres, a proteína torna-se limitante e deveria ser suplementada, primeiro com proteína degradável no rúmen (PDR) para os microrganismos e então com proteína não degradável no rúmen (PNDR) para o animal (Haddad e Castro, 1998). A 
JAYME, C.G. et al. Suplementação de bovinos de corte a pasto durante o período seco. PUBVET, Londrina, V. 7, N. 24, Ed. 247, Art. 1630, Dezembro, 2013.

exigência em proteína degradável no rúmen (PDR) é a exigência proteica dos microrganismos do rúmen, sendo que a disponibilidade de $\mathrm{N}$ prontamente disponível, ou seja, na forma de nitrogênio amoniacal $\left(\mathrm{N}-\mathrm{NH}_{3}\right)$ depende da energia fornecida pela fermentação da matéria orgânica (Cardoso, 1997).

Com objetivo de determinar se a suplementação com amido para dietas com forragem de baixa qualidade é dependente do nível de PDR no suplemento Klevesahlet al. (2003) conduziram um experimento avaliando a associação de amido com diferentes níveis de PDR e concluíram que suplementos que provêm insuficente PDR relativa ao amido exercem efeito negativo sobre a ingestão e digestão da fibra.

O aumento do consumo voluntário pelos bovinos, com a suplementação proteica pode ser atribuído ao aumento na taxa de digestão e de passagem da forragem, resultando em aumento do consumo de energia pelo animal (Haddad e Castro, 1998; Reis et al., 1997; Paulino et al., 1982; Cardoso, 1997).

Segundo Cardoso (1997), a degradabilidade das fontes de proteína e suas combinações, além da quantidade a ser fornecida, também têm importância na formulação de suplemento para animais em pastejo. Entretanto, nem sempre proteína sobrepassante é limitante. A proteína microbiana é que será a limitante quando houver deficiência de proteína degradável no rúmen. Para Reis et al. (1997), a utilização de fontes de proteínas de baixa degradabilidade é adequada quando a disponibilidade de forragem é alta, mas com baixo conteúdo de PB (menor do que 7,0\%). Da mesma forma, quando os animais estão com deficiência energética, devido à falta de forragem ou porque a exigência excede o nível de consumo de energia, o uso de PNDR é recomendado.

A tabela 1 apresenta os dados de alguns trabalhos realizados com suplementação de bovinos de corte a pasto com diferentes gramíneas e suplementos. 
JAYME, C.G. et al. Suplementação de bovinos de corte a pasto durante o período seco.

PUBVET, Londrina, V. 7, N. 24, Ed. 247, Art. 1630, Dezembro, 2013.

Tabela 1: Desempenho de bovinos submetidos à suplementação mineral/concentrada durante o período seco

\begin{tabular}{|c|c|c|c|c|}
\hline $\begin{array}{l}\text { Espécie } \\
\text { Forrageira }\end{array}$ & $\begin{array}{lr}\text { Tipo de } \\
\text { Suplemento }\end{array}$ & $\begin{array}{l}\text { Quantidade } \\
\text { de Suplemento }\end{array}$ & $\begin{array}{l}\text { GMD }^{1} \\
\text { (g/dia) }\end{array}$ & Autor \\
\hline $\begin{array}{l}\text { Brachiária } \\
\text { Brizanta } \\
\text { Marandu }\end{array}$ & $\begin{array}{l}\text { Mistura } \\
\text { Mineral } \\
\text { Concentrado }\end{array}$ & $\begin{array}{l}\text { Livre } \\
0,3 \% \mathrm{PV}^{2} \\
0,6 \% \mathrm{PV} \\
0,9 \% \mathrm{PV}\end{array}$ & $\begin{array}{l}0,400 \\
0,507 \\
0,541 \\
0,640\end{array}$ & $\begin{array}{l}\text { Silva et } \\
\text { al. } 2010\end{array}$ \\
\hline $\begin{array}{ll}\text { Grama } & \text { Estrela } \\
\text { Roxa } & \end{array}$ & $\begin{array}{l}\text { Sal Mineral } \\
\text { Sal } \\
\text { proteinado }\end{array}$ & $\begin{array}{l}\text { Livre } \\
0,29 \mathrm{~kg} / \text { animal/dia } \\
0,40 \mathrm{~kg} / \text { animal/dia }\end{array}$ & $\begin{array}{l}0,250 \\
0,200 \\
0,250\end{array}$ & $\begin{array}{l}\text { Moreira } \\
\text { et al. } \\
2004\end{array}$ \\
\hline $\begin{array}{l}\text { Brachiária } \\
\text { Decumbens }\end{array}$ & $\begin{array}{l}\text { Mistura } \\
\text { Mineral } \\
\text { Concentrado }\end{array}$ & $\begin{array}{l}\text { Livre } \\
0,33 \% \text { PV } \\
0,66 \% \text { PV } \\
1,00 \% \text { PV }\end{array}$ & $\begin{array}{l}0,380 \\
0,750 \\
0,840 \\
0,990\end{array}$ & $\begin{array}{l}\text { Machado, } \\
2012\end{array}$ \\
\hline $\begin{array}{l}\text { Brachiária } \\
\text { Brizanta } \\
\text { Marandu }\end{array}$ & $\begin{array}{l}\text { Mistura } \\
\text { Mineral } \\
\text { Concentrado }\end{array}$ & $\begin{array}{l}\text { Livre } \\
\text { 0,25kg/animal/dia } \\
\text { 0,5 kg/animal/dia } \\
1,0 \mathrm{~kg} / \text { animal/dia } \\
2,0 \mathrm{~kg} / \text { animal/dia } \\
\text { 4,0 kg/animal/dia }\end{array}$ & $\begin{array}{l}0,287 \\
0,195 \\
0,099 \\
0,274 \\
0,372 \\
0,588\end{array}$ & $\begin{array}{l}\text { Baroni, } \\
\begin{array}{l}\text { C. E. S. } \\
\text { et } \\
2010\end{array}\end{array}$ \\
\hline
\end{tabular}

1 - GMD: Ganho de peso médio diário

2 - PV: Peso Corporal 
JAYME, C.G. et al. Suplementação de bovinos de corte a pasto durante o período seco. PUBVET, Londrina, V. 7, N. 24, Ed. 247, Art. 1630, Dezembro, 2013.

Com o propósito de reduzir os custos com a mão-de-obra, algumas pesquisas estão sendo direcionadas no sentido de limitar a suplementação a alguns dias da semana. Simioni et. al (2009) concluíram que a suplementação em dias alternados não prejudica o desempenho animal. Em estudo semelhante, Moraes et. al (2010) observaram que em condições tropicais, os bovinos de corte que recebem suplementação em dias alternados da semana, são mais eficientes em manter a concentração de $\mathrm{NH}_{3}$ no líquido ruminal em níveis adequados para o crescimento e atividade microbiana, não prejudicando as características ingestivas e digestivas dos compostos nitrogenados.

\section{Considerações Finais}

O uso das alternativas de suplementação representa opção para que sistemas de produção de bovinos sejam otimizados possibilitando maior eficiência produtiva na atividade pecuária.

\section{Referências Bibliográficas}

ANUALPEC. Anuário da pecuária brasileira. São Paulo: Instituto FNP, 2011. 378p.

BARONI, C. E. S.; LANA, R. DE P.;MANCIO, A. B.; QUEIROZ, A. C. DE; LEÃO, M. I.; SVERZUT, C. B. Níveis de suplemento à base de fubá de milho para novilhos Nelore terminados a pasto na seca: desempenho, características de carcaça e avaliação do pasto. Revista Brasileira de Zootecnia, v.39, n.1, p.175-182, 2010.

CARDOSO, E.G. Suplementação de bovinos de corte em pastejo (semi-confinamento). In: SIMPÓSIO SOBRE PRODUÇÃO ANIMAL, 4., 1996. Piracicaba. Anais... Piracicaba: FEALD, 1997.

CARVAlho, F. A. N; BARBosA, F. A; MCDOWELL, L. R. Nutrição de bovinos a pasto. Belo Horizonte: PapelForm, 2003.

GOMES JÚNIOR, P; PAULINO, M. F; DETMANN, E; ET AL.. Fontes de proteína em suplementos múltiplos para recria de novilhos durante a época da seca. In: REUNIÃO ANUAL DA SOCIEDADE BRASILEIRA DE ZOOTECNIA, 37., 2000, Viçosa. Anais... Viçosa: SBZ, 2000. (CD-ROOM).

GRANDINI D. V. Produção de bovinos a pasto com suplementos protéicos e/ou energéticos. In: REUNIÃO ANUAL DA SOCIEDADE BRASILEIRA DE ZOOTECNIA, 39., 2001, Piracicaba. Anais...Piaracicaba:SBZ, 2001. (CD-ROOM). 
HADDAD, C.M; CASTRO, F.G.F. Suplementação mineral de novilhos precoces - Uso de sais proteinados e energéticos na alimentação. In: SIMPÓSIO SOBRE PRODUÇÃO INTENSIVA DE GADO DE CORTE, 1998, Campinas. Anais...Campinas, SP: FEALD, 1998.

HENNESSY, D. W. The roles of energy or protein rich supplements in the subtropico for young cattle consuming basal diets that arew low in digestible energy and protein. Journal Agriculture Science, v. 100, n.4, p. 657-666, 1985.

LAZZARINI, I.; DETMANN, E.; SAMPAIO, C.B.Intake and digestibility in cattle fed low-quality tropical forage and supplemented with nitrogenous compounds. RevistaBrasileira de Zootecnia, v.38, n.10, p. 2021-2030, 2009.

LOPES, H. O. S; ARAúJO, V. L; TOMICH, T. R. Efeitos da inclusão de uréia em misturas múltiplas em substituição ao farelo de soja sobre o desempenho e consumo de novilhas de corte. In: REUNIÃO ANUAL DA SOCIEDADE BRASILEIRA DE ZOOTECNIA, 39., 2002, Recife. Anais...Recife:SBZ, 2002. (CD-ROOM).

MACHADO, P.A. S.; VALADARES FILHO, S. C.; VALADARES, R.F. D.; PAULINO, M. F.; PAULINO, P. V. R.; MARCONDES, M. I. Desempenho e exigências de energia e proteína de bovinos de corte em pasto suplementados. Arquivo Brasileiro de Medicina Veterinária e Zootecnia, v.64, n.3, p.683-692, 2012.

MARIN, C. M; ALVES, J. B; BERNARDI, J. R. A. et al. Análise econômica de diferentes níveis de suplementação energético-protéica em relação ao desempenho de bovinos mantidos em pastos de Brachiariadecumbens durante o período das águas. In: REUNIÃO ANUAL DA SOCIEDADE BRASILEIRA DE ZOOTECNIA, 40., 2003, Santa Maria. Anais... Santa Maria: SBZ, 2003. (CD-ROOM).

MOREIRA, F. B.; PRADO, I. N. DO; CECATO, U.;ZEOULA, L. M.; WADA, F. Y.; TORII, M. S. Níveis de Suplementação com Sal Mineral Proteinado para Novilhos Nelore Terminados em Pastagem no Período de Baixa Produção Forrageira.Revista Brasileira de Zootecnia, v.33, n.6, p.1814-1821, 2004 (Supl. 1).

PAULA, N. F. DE; ZERVOUdAKIS, J. T.; CABRAL, L. DA S.;CARVALHO, D. M. G. DE; ZERVOUDAKIS, L. K. H.; MORAES, E. H. B. K. DE; OLIVEIRA, A. A. DE. Frequência de suplementação e fontes de proteína para recria de bovinos em pastejo no período seco: desempenho produtivo e econômico. Revista Brasileira de Zootecnia, v.39, n.4, p.873-882, 2010.

PAULINO, M.F.; ACEDO, T.S.; SALES, M.F.L. Suplementação como estratégia de manejo das pastagens. In: VOLUMOSOS NA PRODUÇÃO DE RUMINANTES, 1., 2003. Jaboticabal. Anais... Jaboticabal: 2003. p. 87-100.

PAULINO, M.F.; DETMANN, E.; VALADARES FILHO, S.C. Suplementação animal em pasto: Energética ou protéica? In: SIMPÓSIO SOBRE MANEJO ESTRATÉGICO DA PASTAGEM, 3., Viçosa, MG, 2006. Anais... Viçosa, MG, 2006.p.359-392.

PAULINO, M. F.; REHFELD, O.A.M.; RUAS, J.R.M. et al.. Alguns aspectos da suplementação de bovinos de corte em regime de pastagens durante a época seca.Informe Agropecuário,v.8, n.89, p. 01-15, 1982.

PAULINO, M. F; KABEYA, K. S; VALADADRES FILHO, S. C. et al. Suplementação de Brachiariadecumbens durante o período das águas. In: REUNIÃO ANUAL DA SOCIEDADE BRASILEIRA DE ZOOTECNIA, 37., 2000, Viçosa. Anais... Viçosa: SBZ, 2000. (CD-ROOM). 
PORTO, M. O.; PAULINO, M. F.; DETMANN, E.; FILHO, S. de C. V.; SALES, M. F. L.; CAVALI, J., NASCIMENTO, M. L. do; ACEDO, T. S. Ofertas de suplementos múltiplos para tourinhos Nelore na fase de recriaem pastagens durante o período da seca: desempenho produtivo ecaracterísticas nutricionais. Revista Brasileira de Zootecnia, v.40, n.11, p.2548-2557, 2011.

REIS, R. A. RODIGUES, L. R. A. PEREIRA, J. R. A. A suplementação como estratégia de manejo de pastagem. In: SIMPÓSIO SOBRE MANEJO DA PASTAGEM, 14., Piracicaba, 1997. Anais... Piracicaba: FEALQ, 1997. p. 1-24.

SILVA, R. R.; PRADO, I. N. DO; CARVALHO, G. G P DE; SILVA, F. F. DA; ALMEIDA, V. V. S. DE; SANTANA JÚNIOR, H. A. DE; PAIXÃO, M. L.; ABREU FILHO, G. Níveis de suplementação na terminação de novilhos Nelore em pastagens: aspectos econômicos. Revista Brasileira de Zootecnia, v.39, n.9, p.2091-2097, 2010.

SIMIONI, F. L.; ANDRADE, I. F DE; LADEIRA, M. M.; GONÇALVES, T. DE M.; MATA JÚNIOR, J. I. DA; CAMPOS, F. R. Níveis e frequência de suplementação de novilhos de corte a pasto na estação seca. Revista Brasileira de Zootecnia, v.38, n.10, p.2045-2052, 2009.

SNIFFEN, C. J; O'CONNOR, J. D; VAN SOEST, P. et al..A net carbohydrate and protein system for evaluating cattle diets.II- Carbohydrate and protein available.Journal Animal Science, v. 70, p. 3562-3577, 1992.In: Http://www.jas.fass.org (acessado em 2 de Setembro de 2012).

THIAGO, L. R. L. Suplementação de bovinos em pastejo: aspectos práticos para seu uso na mantença ou ganho de peso. In: Http://www.cnpgc.embrapa.br (acessado em 2 Setembro de 2012).

TOMICH, T. R; LOPES, H. O. S; PIRES,D. A A. et al. Suplementação com mistura múltipla contendo uréia como fonte de nitrogênio para bovinos em pastagem de braquiária no período das águas. In: REUNIÃO ANUAL DA SOCIEDADE BRASILEIRA DE ZOOTECNIA, 39., 2002, Recife. Anais... Recife:SBZ, 2002. (CD-ROOM).

VAN SOEST, P. J. Nutriional ecology of the ruminants. 2. ed. Ithaca: Cornell University, 1994. 476p.

VILELA, H., DEMTCHENKO, A., VILELA, D.Efeito da adição de uréia à mistura mineral sobre o ganho em peso de bezerros desmamados, em pastejo, durante o período de seca. In: REUNIÃO ANUAL DA SOCIEDADE BRASILEIRA DE ZOOTECNIA, 18, Goiânia, 1981. Anais...Goiânia: SBZ, 1981, p.353.

ZERVOUDAKIS, J. T; PAULINO, M. F; DETMANN, E. Desempenho de novilhas mestiças suplementadas durante o período das águas. In: REUNIÃO ANUAL DA SOCIEDADE BRASILEIRA DE ZOOTECNIA, 37., 2000, Viçosa. Anais... Viçosa: SBZ, 2000. (CD-ROOM). 